\title{
Towards a metagenomic understanding on enhanced biomethane production from waste activated sludge after $\mathrm{pH} 10$ pretreatment
}

Mabel Ting Wong ${ }^{1}$, Dong Zhang ${ }^{2}$, Jun $\mathrm{Li}^{1}$, Raymond Kin Hi Hui ${ }^{1}$, Hein Min Tun ${ }^{1}$, Manreetpal Singh Brar ${ }^{1}$, Tae-Jin Park', Yinguang Chen ${ }^{2^{*}}$ and Frederick C Leung ${ }^{1,3^{*}}$

\begin{abstract}
Background: Understanding the effects of pretreatment on anaerobic digestion of sludge waste from wastewater treatment plants is becoming increasingly important, as impetus moves towards the utilization of sludge for renewable energy production. Although the field of sludge pretreatment has progressed significantly over the past decade, critical questions concerning the underlying microbial interactions remain unanswered. In this study, a metagenomic approach was adopted to investigate the microbial composition and gene content contributing to enhanced biogas production from sludge subjected to a novel pretreatment method (maintaining pH at 10 for 8 days) compared to other documented methods (ultrasonic, thermal and thermal-alkaline).

Results: Our results showed that pretreated sludge attained a maximum methane yield approximately 4-fold higher than that of the blank un-pretreated sludge set-up at day 17. Both the microbial and metabolic consortium shifted extensively towards enhanced biodegradation subsequent to pretreatment, providing insight for the enhanced methane yield. The prevalence of Methanosaeta thermophila and Methanothermobacter thermautotrophicus, together with the functional affiliation of enzymes-encoding genes suggested an acetoclastic and hydrogenotrophic methanogenesis pathway. Additionally, an alternative enzymology in Methanosaeta was observed.

Conclusions: This study is the first to provide a microbiological understanding of improved biogas production subsequent to a novel waste sludge pretreatment method. The knowledge garnered will assist the design of more efficient pretreatment methods for biogas production in the future.
\end{abstract}

Keywords: Wastewater treatment plant, Sludge, Pretreatment, Renewable energy, Biomethane, Pyrosequencing, Metagenomic

\section{Background}

Activated sludge technology is currently the most broadlyimplemented biological method for biomass conversion in wastewater treatment plants (WWTPs) [1]. However, vast quantities of highly organic waste activated sludge (WAS) is produced during this process, and this by-product mass continues to increase with the expansion of population and industry [1-4]. Sludge disposal by landfill or incineration

\footnotetext{
* Correspondence: yg2chen@yahoo.com; fcleung@hkucc.hku.hk

${ }^{2}$ State Key Laboratory of Pollution Control and Resources Reuse, School of Environmental Science and Engineering, Tongji University, 1239 Siping Road, Shanghai 200092, China

${ }^{1} 5$ N01, Kadoorie Biological Sciences Building, School of Biological Sciences, The University of Hong Kong, Pokfulam Road, Hong Kong, Hong Kong

Full list of author information is available at the end of the article
}

may no longer be feasible in the near future due to land scarcity, high waste charge and increasingly stringent environmental control regulations [4,5]. As a result, the strategy for sludge management is shifting towards its reutilization as a potential source for renewable energy [6-8]. In this regard, the anaerobic digestion process represents an attractive means of sludge reduction while producing renewable energy in the form of biogas [8,9]. Identifying efficient ways to improve methane production, a major biogas product from anaerobic digestion, has now become a topic of interest for numerous researchers $[3,10,11]$.

The performance of an anaerobic digestion system has been shown to be tied closely to its microbial community

\section{Biomed Central}


structure [12]. Methane production from WAS is a complex, multi-step process which involves multiple syntrophic interactions within the microbial consortium [13]. Complex compounds (polysaccharides, proteins, nucleic acids, and lipids) are first converted to oligomers and monomers through the action of extracellular hydrolytic enzymes produced by the primary fermenting bacteria [14]. Subsequently, the intermediate products are further transformed into acetate, carbon dioxide, hydrogen and formate by secondary fermenters [14]. The final methanogenesis step is then conducted by methanogenic archaea, whose energy substrates are highly restricted to acetate, $\mathrm{H}_{2}, \mathrm{CO}_{2}$, formate or certain $C_{1}$ compounds [15]. To improve methane yield from sludge, enormous research efforts have been devoted to the development of pretreatment methods to accelerate sludge hydrolysis, including thermal [16], thermal-alkaline [17], ultrasonic [18], mechanical and thermo-chemical methods [19]. Although the field of pretreatment research has progressed significantly in the past decade, many significant questions related to their effects on the underlying microbial interactions remain unanswered.

As the field of pretreatment method research is nearing a threshold, the accomplishments of the past are pushing on the door of microbiology to provide new insights $[20,21]$. In this study, we aimed to investigate the microbial composition and gene content of sludge subjected to our novel pretreatment method (maintaining $\mathrm{pH}$ at 10 for 8 days) which leads to significantly enhanced methane generation compared to other documented methods (ultrasonic, thermal and thermal-alkaline) [4]. It was reported in our previous study that both sludge hydrolysis and shortchain fatty acids (SCFAs; eg. acetic, butyric and propionic acid) accumulation were significantly enhanced when WAS was anaerobically fermented under the condition of pH 10 for 8 days [22]. This phenomenon was suspected to be due to biotic factors rather than abiotic ones (e.g. alkaline hydrolysis) since much higher SCFAs accumulation and enzyme activities were observed in un-autoclaved sludge compared to autoclaved sludge [22]. Further investigation by our group suggested that the solubilization of the sludge matrix, usually a hydrolysis event by the embedded extracellular enzymes, may contribute to the significant SCFAs improvement [23].

In this study, a shotgun metagenomic approach was chosen to study potential shifts in microbial communities and/or gene contents that could help explain elevated productions of methane under our novel pretreatment method $[24,25]$. The latest advances in pyrosequencing technology afford new opportunities to undertake such metagenomic studies to explore the dynamics of microbial communities in time, space or under fluctuating environmental conditions with un-precedented levels of microbial diversity coverage and depth [26-28]. In addition to elucidating the microbiology underpinning the sludge pretreatment process [29], our study sought to improve knowledge of the diversity and physiology of participating syntrophs and methanogens, as well as the mechanism behind the establishment and maintenance of mutualistic cooperation. This knowledge will help to establish a better control over the hydrolysis and methanogenic processes, and promote pretreatment as part of a pertinent strategy for sludge management in WWTP. To the best of our knowledge, this study is the first to adopt a whole genome shotgun approach to link the knowledge between microbiology and engineering of sludge pretreatment methods. Additional statistical soundness was conferred to the surmised conclusion, as the comparative analysis was conducted between meta-datasets generated by the same sequencing method, from well-characterized experimental designs which only differ in known parameters by manipulation.

\section{Results and discussion}

Enhanced methane production by using a newly devised pretreatment strategy

Collected WAS was subjected to a novel pretreatment method (maintaining $\mathrm{pH} 10$ for 8 days) [4], and its effects on methane production enhancement was characterized in this study. Figure 1 illustrates the experimental flowchart of obtaining end samples from the biogas-producing anaerobic digesters. Pretreated sludge for 30 days (P30), un-pretreated sludge for 30 days (UP30), or 40 days (UP40) were used as substrate. Pretreated sludge was significantly more effective in producing biogas, as total gas volume produced on day $8(604.32 \mathrm{ml} / \mathrm{g}$ VSS-added $)$ is 7.71 and 1.67 times of that in the un-pretreated sludge bioreactor on day $8(78.43 \mathrm{ml} / \mathrm{g}$ VSS-added) and day 16 (360.99 ml/g VSS-added), respectively (Figure 2A-B). Methane production was $389.8 \mathrm{~mL}-\mathrm{CH} 4 / \mathrm{g}$ VSS-added using pretreated sludge as a substrate, which was 3.78 times that

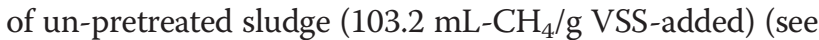
Figure $2 \mathrm{C}$ ). The generated methane on average constituted $70.5 \%$ and $59.1 \%$ of the total generated gas composition in the two respective bioreactors, while the rest was primarily $\mathrm{CO}_{2}$ (pretreated sludge, 3.6\%; un-pretreated sludge, 9.2\%) and other small amounts of $\mathrm{N}_{2}, \mathrm{H}_{2}, \mathrm{NH}_{3}$ and $\mathrm{H}_{2} \mathrm{~S}$ (data not shown) (Figure 2D-E). It is worthwhile to note that the methane content was increased by $19.3 \%$, and carbon dioxide content was decreased by $60.9 \%$ after the pretreatment. The reproducibility of this new pretreatment strategy validated the experimental success seen before and its technical robustness. This warranted investigation of biological mechanisms behind this significant bioreactor improvement in performance.

\section{Biogas producing microbial community residing in anaerobic digester inferred by metagenome sequencing} To analyze biogas-producing microbes residing in our studied bioreactors in terms of community structure, 


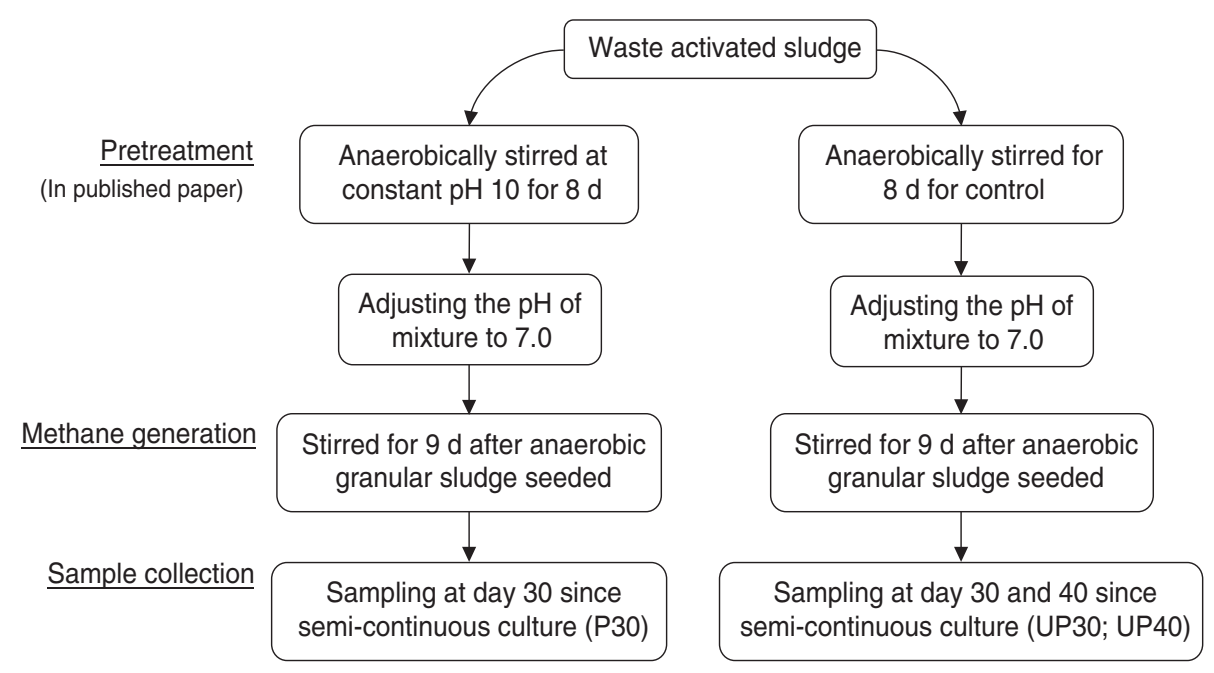

Figure 1 Sample preparation (P30, UP30 and UP 40) from pretreated and un-pretreated sludge bioreactors.

gene content, metabolic capabilities and the role of specific organisms in biogas formation, a metagenomic approach using the 454 pyrosequencing was used. Statistical data summarizing the output sequencing quantity of the three independent runs of P30, UP30 and UP40 is given in Table 1 . To detect differentially abundant features between the microbial communities, we used the Meta Genome Rapid Annotation using Subsystem Technology (MG-RAST) analysis pipeline, which has shown to be applicable to various metagenomic data performing taxonomic classification as well as functional annotation [30].

Composition of the biogas-producing microbial community was obtained by taxonomic classification of reads base on the M5NR database on the MG-RAST platform. In all three reactor samples, Bacteria were the dominant superkingdom (Table 1). Domain-based allocation was primarily assigned to Bacteria (82.13\% on average) and Archaea (11.86\% on average), whilst the assigned reads to Eukaryota and Viruses altogether accounted for less than half a percent (Table 1). The bacterial proportion of the microbial community in P30 was the highest (85.46\%) followed by UP30 (81.82\%) and UP40 (79.10\%). As for the Archaea domain, it ranged from $8.32 \%$ in P30, to $12.13 \%$ in UP30, and to $15.13 \%$ in UP40. The clustering pattern shown in Additional file 1 provides a graphical representation of the overall taxonomic similarity-the microbiomes of the unpretreated sludge bioreactors (UP30 and UP40) displayed high resemblance, in which the mature unpretreated sludge bioreactor (UP40, operated for longer time) is comparatively closer to the significantly diverse pretreated sludge bioreactor. The result provided the first insight into both the temporal dynamic and the enormous impact of pretreatment on microbiology. Downstream analyses focused on the
Bacteria and Archaea domains (unless otherwise specified, the percentages below are representative of the identified reads within each domain per independent run).

Within the Bacteria domain, the top abundant phyla were Proteobacteria (UP30, 32.17\%; UP40, 30.45\%; P30, 42.28\%), Bacteroidetes (UP30, 22.91\%; UP40, 22.25\%; P30, 23.38\%), Firmicutes (UP30, 16.54\%; UP40, 17.65\%; P30, 10.97\%), Actinobacteria (UP30, 7.13\%; UP40, 6.94\%; P30, 6.83\%) and Chloroflexi (UP30, 5.00\%; UP40, 5.21\%; P30, 3.37\%), they collectively account for over 0.7 of the bacterial reads (normalized between 0 and 1) for each of the three bioreactors (Figure 3A). Proteobacteria, Bacteroidetes and Firmicutes have been reported to be dominant phyla as well in similar analysis of anaerobic digestion of sludge [9]. Further resolution at the class level revealed that the microbial compositions overlapped between the bioreactor samples. To be more precise, the dominant bacterial lineages presented in this study were related to anaerobic digestion, including Bacteroidia (UP30, 13.50\%; UP40, 12.69\%; P30, 8.90\%), $\delta$-proteobacteria (UP30, 13.08\%; UP40, 12.71\%; P30, 8.93\%), Clostridia (UP30, 11.42\%; UP40, 12.21\%; P30, 7.31\%), $\gamma$-proteobacteria (UP30, 8.12\%; UP40, 7.90\%; P30, 11.18\%), Actinobacteria (class) (UP30, 7.37\%; UP40, 7.20\%; P30, 7.06\%), $\alpha$-proteobacteria (UP30, 5.78\%; UP40, 5.28\%; P30, 9.33\%), $\beta$-proteobacteria (UP30, 5.73\%; UP40, 4.86\%; P30, 13.58\%), Bacilli (UP30, 5.16\%; UP40, 5.25\%; P30, 3.53\%), Flavobacteria (UP30, 4.70\%; UP40, 4.76\%; P30, 6.98\%) and Chloroflexi (class) (UP30, 2.65\%; UP40, 2.56\%; P30, 1.84\%) (Figure 3B).

With time, there was moderate temporal variation in the relative abundances of these bacterial members in the anaerobic digester fed with un-pretreated sludge (UP30 and UP40). While the relative proportion of these communities 

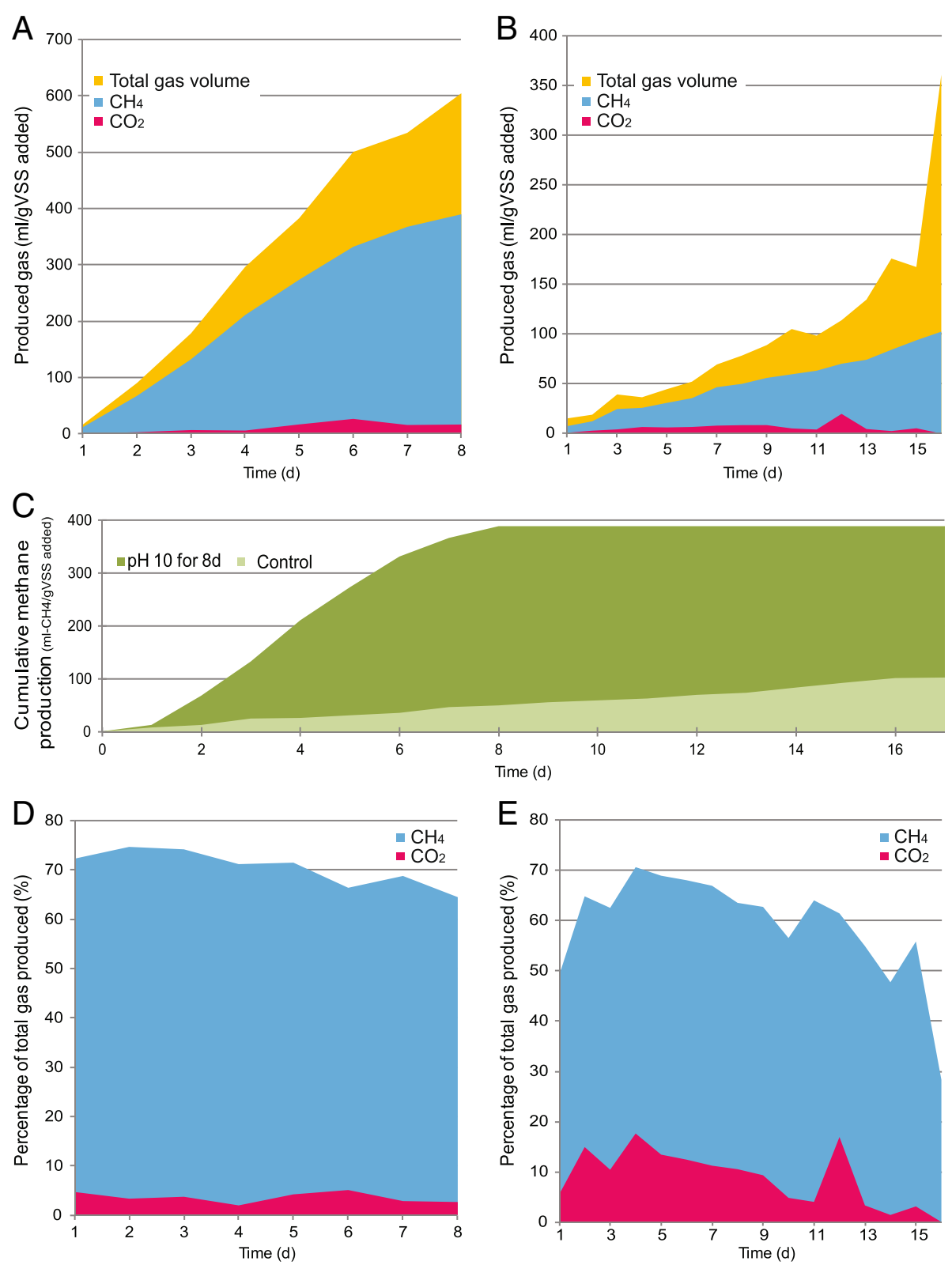

Figure 2 Biogas production profile of pretreated and un-pretreated sludge bioreactors. Efficiency of biogas production in (A) the pretreated sludge bioreactor is significantly higher than (B) the un-pretreated sludge bioreactor, giving rise to a 7.71-fold difference in the produced volume at day 8 . (C) The cumulative methane production was $389.8 \mathrm{~mL}-\mathrm{CH}_{4} / \mathrm{g}$ VSS-added using pretreated sludge as substrate, 3.78 times of that with un-pretreated sludge $\left(103.2 \mathrm{~mL}-\mathrm{CH}_{4} / \mathrm{g}\right.$ VSS-added) as substrate. Figure 2 (D-E) display methane and carbon dioxide percentages produced by $(\mathbf{D})$ pretreated and $(\mathbf{E})$ un-pretreated sludge bioreactor, respectively; while methane is the major biogas component in both reactors, the methane content was increased by $19.3 \%$ with a decrease in carbon dioxide content by $60.9 \%$ after pretreatment.

remained comparable between UP30 and UP40, a larger extent of differences could be observed when P30 was taken into comparison for certain lineages. The over-represented bacterial members in P30 included $\alpha$-proteobacteria (9.33\%), $\beta$-proteobacteria (13.58\%) and $\gamma$ proteobacteria $(11.18 \%)$; which are respectively $69.06 \%$, $158.21 \%$ and $39.60 \%$ more than UP30 and UP40 on average. Overall, these sequences were originated from the
WAS substrate, AGS inoculum and the biogas-producing symbiont within the system, hence the differences observed in their relative abundance were attributable to the sole variable of either using pretreated or un-pretreated sludge in the bioreactors. These results suggested that the bacterial communities that underlie the anaerobic digesters were dynamic, and they responded rapidly to the pretreated sludge substrate and change substantially over time. 
Table 1 Statistics of 454 GS Junior pyrosequence datasets presented in this study

\begin{tabular}{lccc}
\hline Sample & P30 & UP30 & UP40 \\
\hline Pretreatment & pH10 for 8d & Un-pretreated & Un-pretreated \\
Semi-continuous culture & $30 \mathrm{~d}$ & $30 \mathrm{~d}$ & $40 \mathrm{~d}$ \\
Sequences count & 151,676 & 114,694 & 134,522 \\
Mean sequence length & $392 \pm 120 \mathrm{bp}$ & $289 \pm 99 \mathrm{bp}$ & $425 \pm 115 \mathrm{bp}$ \\
Archaea & $8.32 \%$ & $12.13 \%$ & $15.13 \%$ \\
Bacteria & $85.46 \%$ & $81.82 \%$ & $79.10 \%$ \\
Eukaryota & $0.45 \%$ & $0.30 \%$ & $0.48 \%$ \\
Viruses & $0.01 \%$ & $0.02 \%$ & $0.02 \%$ \\
other sequences & $0.01 \%$ & $0.01 \%$ & $0.00 \%$ \\
unassigned & $5.75 \%$ & $5.72 \%$ & $5.28 \%$ \\
\hline
\end{tabular}

Legends: By taxonomic classification based on M5NR database, Bacteria ( $82.13 \%$ on average) and Archaea (11.86\% on average) are the dominant domains, with variable proportions in the bioreactor samples. UP 30 and UP40 are collected from same reactor at different time since semi-continuous culture.

Based on the phylogenetic affiliation of the metagenomic sequences, it is possible to form hypotheses regarding the metabolic functions of the groups [9]. Proteobacteria are microorganisms involved in the initial steps of degradation, studies have shown that they are the main consumers of propionate, butyrate and acetate [31]. Bacteroidetes are known proteolytic bacteria, responsible for the degradation of protein and subsequent fermentation of amino acids into acetate for acetoclastic methanogens [31,32]. Concerning Firmicutes, they are syntrophic bacteria which degrade volatile fatty acids such as butyrate [31]. The $\mathrm{H}_{2}$ generated from this process could be then uptaken by the hydrogenotrophic methanogens [33]. The bacterial class Clostridia is frequently found in co-culture with other species in biomasss conversion systems and it includes a number of anaerobic species that are commonly associated with the decomposition of lignocelluloses and municipal solid waste $[34,35]$. As for Chloroflexi, this group is often found in various wasterwater treatments such as anaerobic digesters and biological nutrient removal processes; their potential role in carbohydrate degradation has been reported in several studies [31,36-38]. Overall, the resident bacteria manifested in the bioreactors represented a biomass decomposing community.

Archaeal representatives were less diverse and consisted of only three major families of methanogens, belonging to Methanosarcinaceae, Methanobacteriaceae and Methanosaetaceae (Table 2). The predominance of selected methanogen lineages in the Archaeal domain (represented as percentage of total identified reads in Archaea) has been observed in both production and laboratory-scale biogas reactors $[23,39,40]$, and concluded in a recent meta-analysis of the collective microbial diversity [41,42]. At the genus level, Methanosarcina was determined to be the most abundant methanogen in all three bioreactors $(13.51 \%$ on average-UP30, 15.10\%; UP40, 13.32\%; P30, 12.10\%), while Methanosaeta (10.67\% on average-UP30, 13.13\%; UP40, 10.31\%; P30, 8.56\%) and Methanothermobacter (10.35\% on averageUP30, 10.73\%; UP40, 9.41\%; P30, 10.91\%) contributed to slightly lesser portions. Anaerobic digesters are typical habitats to these three genera of methanogens [43], and the enrichment of Methanosarcina species was in congruence with other evaluation studies on primary sludge and WAS anaerobic digesters [44,45]. The observation of a lesser portion of Methanothermobacter was expected, as the operating condition of the bioreactor (approximate $35^{\circ} \mathrm{C}$ ) was not in favour of this thermophilic Archeon's proliferation $\left(55-65^{\circ} \mathrm{C}\right)[43]$.

Methanosaeta species were observed to be more abundant in samples of bioreactor digesting unpretreated sludge (UP30; 13.13\%) than that with pretreated sludge (P30; 8.56\%), but the population decreases with time (UP40; 8.56\%). A similar observation was found in an earlier surveillance of the methanogenic population dynamics in anaerobic digesters, where the hitherto abundant Methanosaeta population decreased rapidly as the acetate concentration increased [12]. As acetoclastic methanogens, both Methanosarcina and Methanosaeta are able to split acetate, oxidize the carboxyl-group to $\mathrm{CO}_{2}$ and reduce the methyl group to $\mathrm{CH}_{4}$ [43]. At the same time, while Methanosarcina thrive in environments with high acetate concentration; lower acetate concentrations benefit the dominance of Methanosaeta owing to their high affinity for acetate [12,46-48]. As aforementioned, an enhanced bioproduction of acetic acid was reported in the pretreated sludge [4], the revealed shift in the methanogenic community could therefore be interpreted as an ecological consequence $[30,49,50]$ of the sludge pretreatment.

\section{Methane production via acetoclastic and hydrogenotrophic pathways}

To identify the methane-producing organisms in the bioreactor samples, taxonomic and functional affiliation of the metagenomic reads were evaluated in parallel (represented as percentage of total identified methanogens). On the species level, it is common to all three bioreactor samples that Methanosaeta thermophila (12.36\% on average-UP30, 14.48\%; UP40, 12.36\%; P30, 10.25\%) and Methanothermobacter thermautotrophicus (9.34\% on average-UP30, 9.50\%; UP40, 8.59\%; P30, 9.94\%) are the over-represented methanogens (Table 2). Here, Methanosarcina species were not represented as one of the top dominant methanogens $(13.51 \%$ on averageUP30, 15.10\%; UP40, 13.32\%; P30, 12.10\%), this observation was linked to the intra-divergence of each family 


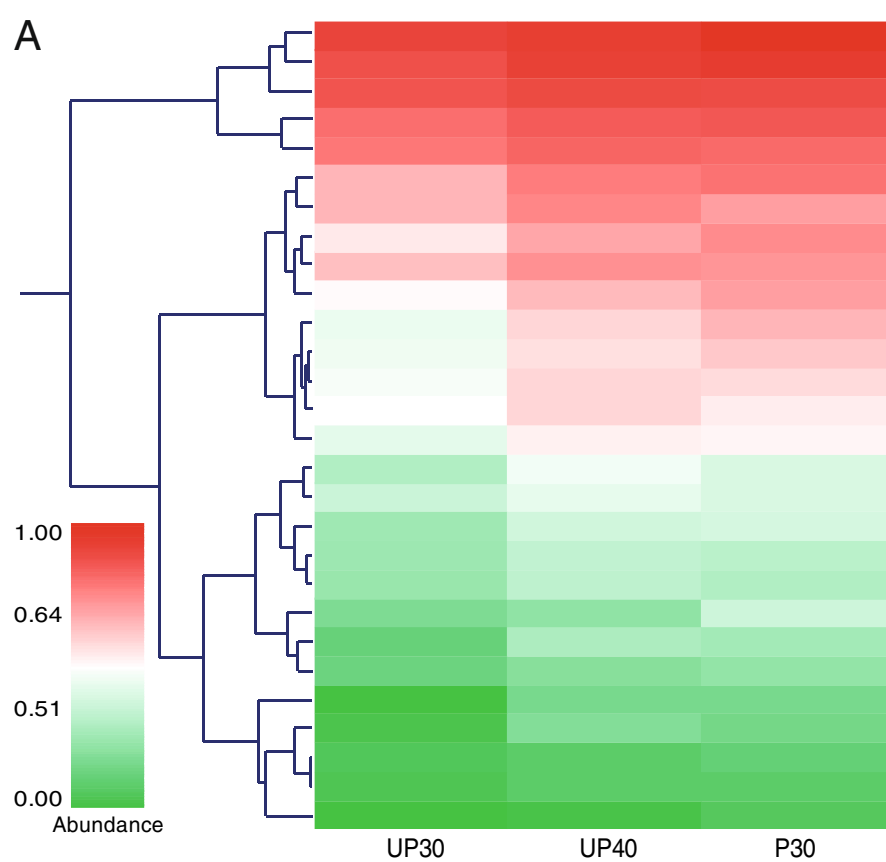

B

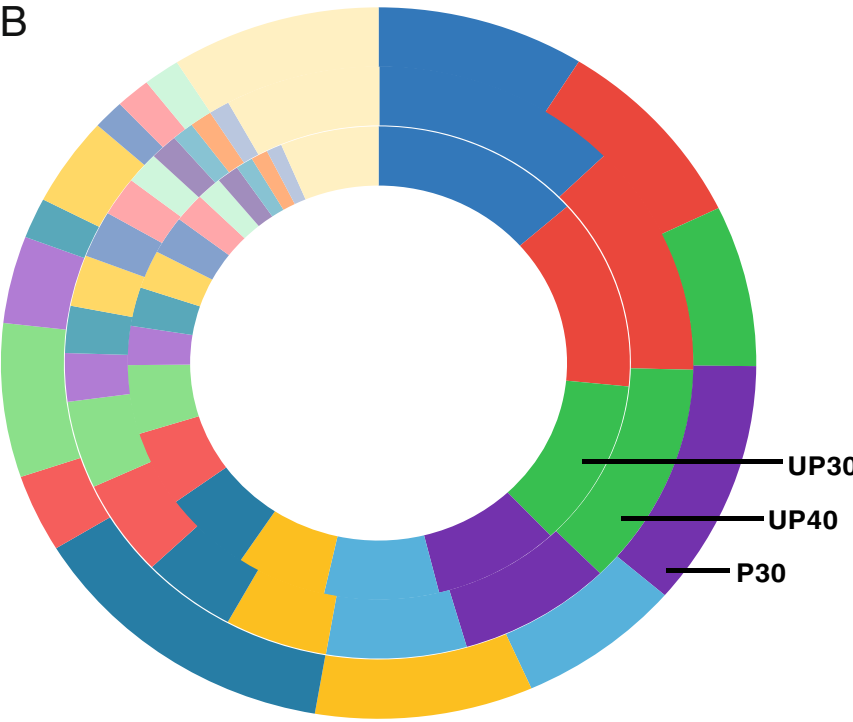

Proteobacteria

Bacteroidetes

Firmicutes

Actinobacteria

Chloroflexi

Cyanobacteria

Thermotogae

Planctomycetes

Chlorobi

Acidobacteria

Verrucomicrobia

DeinococcusThermus

Spirochaetes

Synergistetes

unclassified Bacteria

Fusobacteria

Aquificae

Nitrospirae

Dictyoglomi

Deferribacteres

Gemmatimonadetes

Lentisphaerae

Chlamydiae

Elusimicrobia

Tenericutes

Chrysiogenetes

Fibrobacteres

Candidatus Poribacteria

- Bacteroidia

- Deltaproteobacteria

Clostridia

- Gammaproteobacteria

- Actinobacteria (class)

- Alphaproteobacteria

- Betap roteobacteria

- Bacilli

Flavobacteria

Sphingobacteria

- Chloroflexi (class)

Cytophagia

- Thermotogae (class)

- Chlorobia

Planctomycetacia

- Anaerolineae

- Synergistia

Spirochaetes (class)

Deinococci

Others

Figure 3 Bacterial community in pretreated and un-pretreated sludge bioreactor at day $\mathbf{3 0}$ and $\mathbf{4 0}$. (A) Proteobacteria, Bacteroidetes, Firmicutes, Actinobacteria and Chloroflexi represent top abundant phyla, all account for over 0.7 of the bacterial reads (normalized between 0 and 1) in the bioreactors. Abundance is displayed by both colour scheme and clustering dendrogram. (B) Bacterial consortiums which represent an anaerobic digestion community were manifested with overlapped dominant lineages in the bioreactors, with over-represented $a-, \beta-$ and $\gamma$-proteobacteria in the sludge bioreactor consequent to the pretreatment (compare inner and outermost rings).

[9]. M. thermophila is an obligate methanogen which consumes acetate only [51], whereas $M$. thermautotrophicus conserves energy by using $\mathrm{H}_{2}$ to reduce $\mathrm{CO}_{2}$ to $\mathrm{CH}_{4}$ $[33,52]$. While the $\mathrm{pH}$ was adjusted to be within the optimum range (7.0) for the two dominate methanogens after pretreatment (Figure 1), it was interesting to detect the prevalence of the thermophilic $M$. thermautotrophicus in the bioreactors that operated at mesophilic temperature [53]. At the same time, functional enzyme-encoding genes for the two methanogenesis pathways were identified with reference to KEGG and Metacyc pathway database entries (Figure 4, Additional file 2) [54,55]. Nonetheless, based on these results, it was evinced that the production of methane in the studied bioreactors was performed by methanogenic Archaea via acetoclastic and hydrogenotrophic pathways.

Acetoclastic and hydrogenotrohpic pathways are indeed common methanogenesis pathways reported in 
Table 2 Relative abundance of Archaea in pretreated and un-pretreated sludge bioreactors at day $\mathbf{3 0}$ and $\mathbf{4 0}$

\begin{tabular}{lccc}
\hline Archaeal taxonomic affiliation & \multicolumn{3}{c}{ Percentage of all Archaeal reads } \\
\cline { 2 - 4 } (phylum/ family/ genus/ species) & UP30 & UP40 & $95.60 \%$ \\
Euryarchaeota & $97.60 \%$ & $20.56 \%$ & $19.14 \%$ \\
Methanosarcinaceae & $23.11 \%$ & $13.32 \%$ & $12.10 \%$ \\
$\quad$ Methanosarcina & $15.10 \%$ & $18.61 \%$ & $21.44 \%$ \\
Methanobacteriaceae & $20.81 \%$ & $9.41 \%$ & $10.91 \%$ \\
$\quad$ Methanothermobacter & $10.73 \%$ & $8.59 \%$ & $9.94 \%$ \\
$\quad$ Methanothermobacter thermautotrophicus & $9.50 \%$ & $11.03 \%$ & $9.19 \%$ \\
Methanosaetaceae & $14.00 \%$ & $10.31 \%$ & $8.56 \%$ \\
$\quad$ Methanosaeta & $13.13 \%$ & $12.36 \%$ & $10.25 \%$ \\
$\quad$ Methanosaeta thermophila & $14.48 \%$ & $3.61 \%$ & $4.40 \%$ \\
Crenarchaeota & $2.33 \%$ & $0.45 \%$ & $0.37 \%$ \\
Korarchaeota & $0.00 \%$ & $0.27 \%$ & $0.37 \%$ \\
Thaumarchaeota & $0.05 \%$ & $0.07 \%$ & $0.00 \%$ \\
Nanoarchaeota & $0.02 \%$ & &
\end{tabular}

Legends: Archaeal domain consists three major families belonging to Methanosarcinaceae, Methanobacteriaceae and Methanosaetacea, while Methanosarcina, Methanosaeta and Methanothermobacter represent top abundant methanogens on the genus level. The decrease in abundance of Methanosarcina-related species in P30 was correlated with an enhanced bioproduction of acetate in the pretreated sludge. Except for phylum level, only candidates of abundance $>8 \%$ are presented. Species are represented as percentage of all methanogens.

various reports $[42,56]$; the affirmation of these pathways permitted subsequent in-depth investigation of the encompassed enzymology. The first step in acetoclastic methanogenesis is the formation of acetylCoA from acetate [51]. Analysis of the recently completed genome of Methanosaeta thermophilia confirmed that the majority of the acetoclastic pathway are similar for Methanosaeta and Methanosarcina, except the enzymes employed for the first step of catalyzation [51]. It was proposed that acetoclastic methanogenesis in Methanosaeta proceeded with a modified version of the pathway compared with Methanosarcina, which utilizes the acetate kinase/phosphotransacetylase pathway to convert acetate to acetyl-CoA $[57,58]$. Taking $M$. thermophila as an example, its genome does not include a readily identifiable acetate kinase, and it has been postulated that this archeon utilizes an acetate transporter coupled with acetyl-CoA synthetases to convert acetate to acetyl-CoA, and the hydrolysis of pyrophosphate by inorganic pyrophosphatase (PPase) drives this reaction forward [51]. In this study, the analysis of metagenomic datasets using SEED annotation indicated the presence of acetyl-CoA synthetases (EC 6.2.1.1) and inorganic pyrophosphatase (EC 3.6.1.1) in the compiled Methanosaeta bin. While the sequencing depth might account for the absence of genes for the acetate kinase/phosphotransacetylase pathway, the discovery of these two enzymes advocated an alternative pathway in acetotrohpic methanogenesis for Methanosaeta [41]. Results from a recent study on a terephthalate-degrading bioreactor supported this hypothesis [41].

\section{Functional affiliation related to higher methane production after sludge pretreatment}

Degradation of the highly organic polymers represents the first and overall rate-limiting step for the mineralization of organic matter in activated sludge and anaerobic digested sludge treatment systems [59-61]. In our work, the studied pretreatment involved alteration of $\mathrm{pH}$, which is an important parameter affecting both bacterial activity and metabolite pathways. KO-based annotations were used to understand how these phylogenetic trends could be used to predict the metabolic potential of these microbes. Figure 5 shows the subsystems that are related to higher methane production, including metabolism of amino acids, energy, carbohydrates, nucleotides, lipids, cofactors and vitamins, xenobiotics, as well as the fermentation of different substrates. These results revealed a general elevated expression of these faculties in the bioreactors fed with un-pretreated sludge over time (compare UP30 and UP40), whereas these levels were highest in the bioreactor digesting pretreated sludge (P30). Distribution of the functional systems was most divergent in P30, which showed predominance in metabolism consistent with a community shifted towards an enhanced biomass degradation metabolism. Herewith, the downstream analysis focused on the degradation of carbohydrates for a number of reasons. Firstly, the matrix of extra-cellular polymeric substances (EPS) that crosslink cells together remains the primary solid part of biological sludge, of which the polysaccharide is the predominant component [62-64]. Secondly, complex carbohydrate is the commonplace recalcitrant in the hydrolysis process, and bioprospecting 


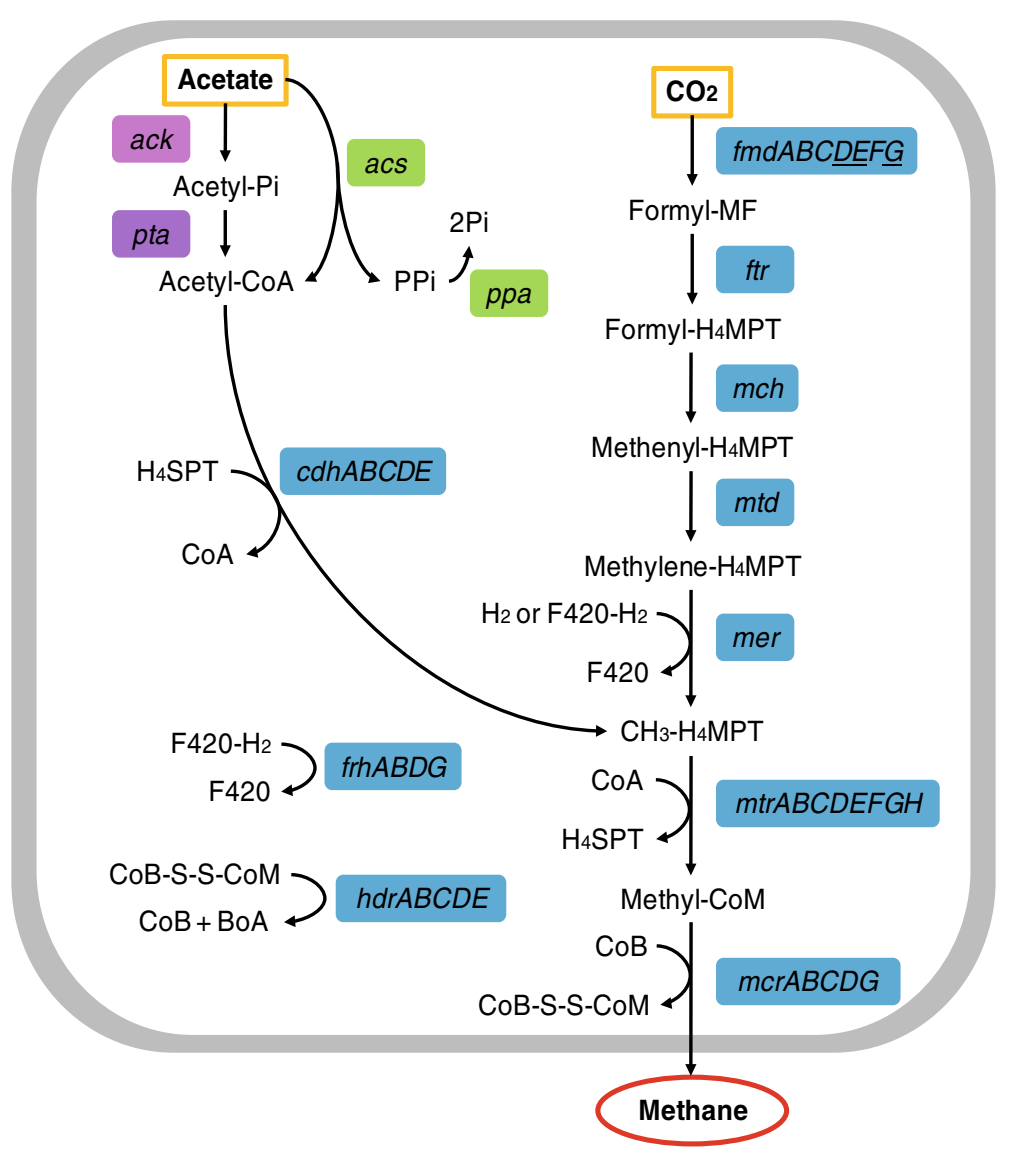

Figure 4 Reconstruction of methanogenesis pathways occurring in the bioreactors using identified genes. Positive identifications in meta-datasets are shown in colored boxes, with negative identifications shown underlined. Gene candidates for the formation of acetyl-CoA from acetate in the Methanosaeta bin are displayed in green boxes, and negative identifications particular to this bin are shown in purple boxes. See Additional file 2 for full form of abbreviated names and detailed identification counts.

for carbohydrate active enzymes is a topic of interest in metagenomics [65]. As a result, the focus of our study was hence placed on the degradation of this dominant recalcitrant component. (Please see Additional file 3 for further insights towards protein and lipid degradation.)

As sequencing technology provides access to a remarkable array of microbial functional capacity, sequence-based data mining is an important prospect in metagenomic projects $[66,67]$. To understand how the microbial community mediates the solibulization of the sludge matrix, a carbohydrate-active enzyme (CAZy) characterization of the metagenomic datasets was performed after $a b$ initio gene prediction $[68,69]$. Conventional sequence homologybased enzyme discovery introduces a bias towards the identification of candidates similar to known enzymes, rather than enzymes with low sequence identity and potentially divergent biochemical properties [66]. The entries in the CAZy database contains both experimentally verified and putative carbohydrate-active enzyme domains, hence this search strategy would be able to provide a better insight into the catalysis of biochemical reactions [68,70].
In this study, a total of 1917 and 107 gene modules were recognized across 52 glycosyl hydrolases $(\mathrm{GH})$ and 9 carbohydrate binding modules (CBM) respectively (Tables 3 and 4). GH is defined as a widespread group of enzymes which hydrolyzes the glycosidic bond between carbohydrates or between that and a non-carbohydrate moiety [68]. On the other hand, CBM are contiguous amino acids within a carbohydrate-active enzyme with a discreet fold which bears the carbohydrate-binding activity [68]. In contrast to the small number of enzymes devoted to the hydrolysis of the main chain of cellulose, hemicelluloses and pectins (GH 5, 6, 7, 8, 9, 12, 44, 45, 48 and 74), all three metagenomes displayed a variety of enzymes that digest the side chains of these polymers and oligosaccharides. Families of GH 2 and 3, which contain a large range of glycosidases cleaving nonreducing carbohydrates in oligosaccharides and the side chains of hemicelluloses and pectins, were particularly abundant in the bioreactor samples $(29.10 \%$ of all GHUP30, 27.56\%; UP40, 29.55\%; P30, 24.20\%). CBM 48 was the most dominant in the three metagenomes, it binds 


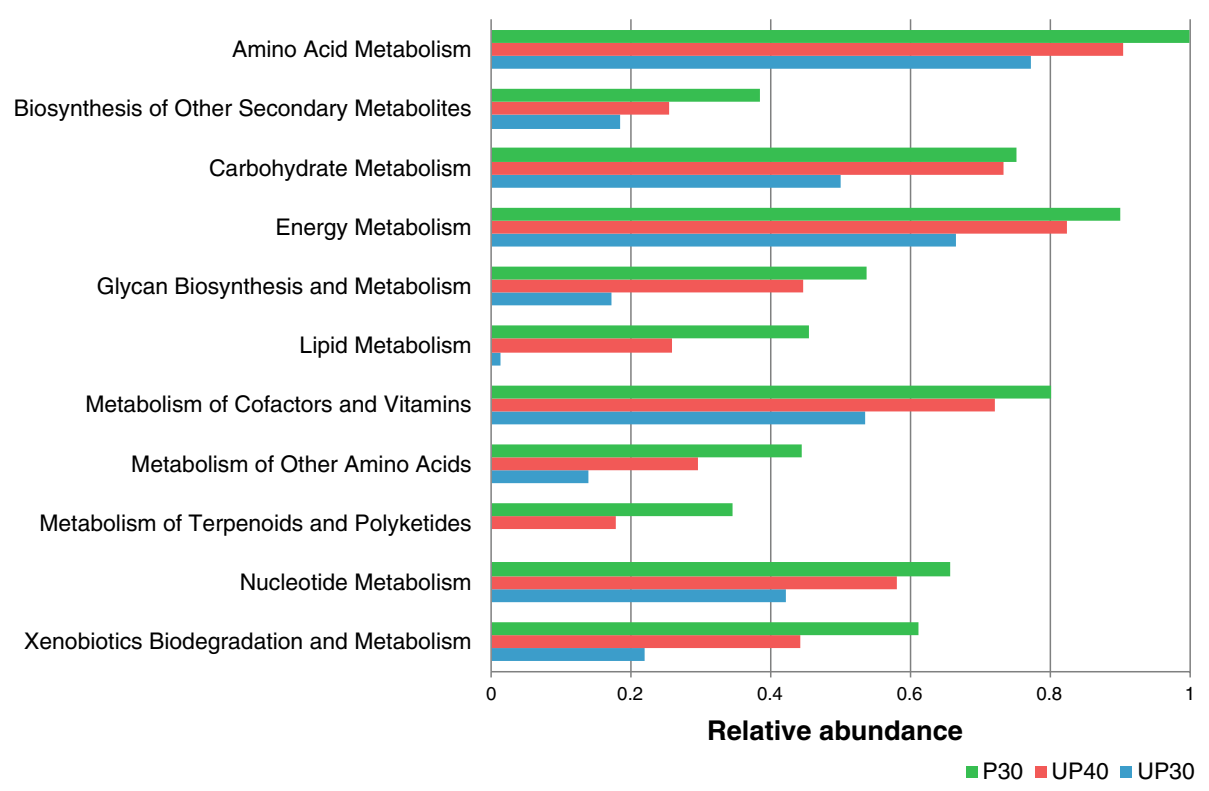

Figure 5 Relative abundance of functional reads affiliated to metabolisms associated to higher methane production using KO database. Expression of these faculties in the un-pretreated sludge bioreactor gradually elevated over time (compare UP30 and UP40), and were highest in pretreated-sludge bioreactor (P30).

glycogen and is commonly found in a range of enzymes that act on branched substrates, such as the hydrolysis of glycogen, amylopectin and dextrin by isoamylase, pulluanase and branching enzyme. Overall, the number of GH hit returns appeared to increase with time in the bioreactor fed with un-pretreated sludge (468 counts in UP30; 792 counts in UP40); while the bioreactor digesting the pretreated sludge harboured 1.40 times the $\mathrm{GH}$ count in the control counterpart at the same time. As for CBM, P30 (51 counts) had a higher abundance than UP40 (38 counts), and made up to approximately 2.83 times that of UP30. Generally, there appeared to be a dynamic process in enzymology within the anaerobic digesters with time and substrate nature The heightened $\mathrm{GH}$ and CBM abundance in the bioreactor with pretreated sludge may possibly correlate with the higher sludge solubilization proposed in previous studies [23].

\section{Conclusions}

The treatment and disposal of excess sludge accumulation represents a bottleneck in wastewater treatment plants worldwide due to environmental, economic, social and legal factors. Reduction of excess sludge is becoming one of the biggest challenges in biological wastewater treatment $[71,72]$. The anaerobic digestion process is a promising technique, along with which waste is eliminated and methane is produced as a valuable renewable energy source. Understanding the impact of pretreatment on the microbiology at different stages of anaerobic digestion is important; it ultimately impacts the performance of a bioreactor. This study represents the first attempt to gain an in-depth metagenomic perspective, with regard to taxonomic and functional aspects, on increased biogas (methane) production when a newly devised pretreatment method is used. Dual taxonomic and functional analysis indicated the microbial and metabolic consortium shifted extensively towards enhanced biodegradation, also seen in the methanogenesis pathways. Altogether, these results presented here help further microbiological understanding in sludge pretreatment research for anaerobic digestion. As microbiology is the ultimate driver for the anaerobic digestion process, this new perspective encourages a closer engagement between the engineering and microbiology knowledge pools. Further studies involving deeper sequencing of the metagenomes to characterize the decomposing and methanogenic microbiome at higher frequency and replicate number parallel to the physical-chemical characterization are required for each WAS pretreatment intervention.

\section{Methods}

\section{Collection of waste activated sludge and anaerobic granular sludge}

The waste activated sludge (WAS) used as substrate for methane production was collected from the secondary sedimentation tank of a municipal wastewater treatment plant in Shanghai, China. The anaerobic granular sludge (AGS) used as the inoculum for methane production was obtained from the upward-flow anaerobic sludge blanket (USAB) reactor of a food wastewater treatment 
Table 3 Identification of glycoside hydrolase (GH) family classified by CAZy database

\begin{tabular}{|c|c|c|c|c|c|c|c|c|c|}
\hline \multirow[b]{2}{*}{ CAZy GH family } & \multirow[b]{2}{*}{ Pfam model } & \multicolumn{3}{|c|}{ Number of counts } & \multirow[b]{2}{*}{ CAZy GH family } & \multirow[b]{2}{*}{ Pfam model } & \multicolumn{3}{|c|}{ Number of counts } \\
\hline & & UP30 & UP40 & P30 & & & UP30 & UP40 & P30 \\
\hline $\mathrm{GH} 1$ & PF00232.12 & 11 & 14 & 15 & $\mathrm{GH} 38 \mathrm{C}$ & PF07748.7 & 20 & 42 & 15 \\
\hline $\mathrm{GH} 2$ & PF00703.15 & 7 & 27 & 28 & GH 39 & PF01229.11 & 2 & 1 & 6 \\
\hline $\mathrm{GH} 2 \_\mathrm{C}$ & PF02836.11 & 18 & 38 & 31 & $\mathrm{GH} 42$ & PF02449.9 & 8 & 18 & 12 \\
\hline GH 2_N & PF02837.12 & 26 & 61 & 44 & $\mathrm{GH} 42 \mathrm{C}$ & PF08533.4 & 0 & 3 & 3 \\
\hline $\mathrm{GH} 3$ & PF00933.15 & 49 & 69 & 59 & $\mathrm{GH} 42 \mathrm{M}$ & PF08532.4 & 7 & 5 & 4 \\
\hline GH 3_C & PF01915.16 & 29 & 39 & 33 & $\mathrm{GH} 43$ & PF04616.8 & 12 & 27 & 33 \\
\hline $\mathrm{GH} 4$ & PF02056.10 & 9 & 20 & 10 & $\mathrm{GH} 44$ & PF12891.1 & 1 & 1 & 2 \\
\hline $\mathrm{GH} 8$ & PF01270.1 & 0 & 0 & 1 & $\mathrm{GH} 4 \mathrm{C}$ & PF11975.1 & 8 & 18 & 8 \\
\hline $\mathrm{GH} 9$ & PF00759.1 & 9 & 5 & 7 & GH 53 & PF07745.7 & 1 & 1 & 10 \\
\hline GH 10 & PF00331.14 & 4 & 10 & 11 & GH 57 & PF03065.1 & 22 & 38 & 12 \\
\hline GH 15 & PF00723.1 & 2 & 2 & 7 & GH 62 & PF03664.7 & 0 & 1 & 0 \\
\hline GH 16 & PF00722.15 & 11 & 9 & 9 & GH 63 & PF03200.10 & 1 & 1 & 0 \\
\hline GH 17 & PF00332.12 & 0 & 0 & 1 & $\mathrm{GH} 65 \mathrm{C}$ & PF03633.9 & 2 & 2 & 3 \\
\hline GH 18 & PF00704.22 & 7 & 11 & 7 & $\mathrm{GH} 65 \mathrm{~m}$ & PF03632.9 & 19 & 5 & 12 \\
\hline GH 19 & PF00182.13 & 0 & 0 & 1 & GH $65 \mathrm{~N}$ & PF03636.9 & 3 & 8 & 5 \\
\hline GH 20 & PF00728.16 & 25 & 40 & 22 & GH $67 \mathrm{C}$ & PF07477.6 & 2 & 5 & 1 \\
\hline $\mathrm{GH} 20 \mathrm{~b}$ & PF02838.9 & 12 & 6 & 7 & $\mathrm{GH} 67 \mathrm{M}$ & PF07488.6 & 3 & 6 & 7 \\
\hline GH 25 & PF01183.14 & 7 & 8 & 8 & GH $67 \mathrm{~N}$ & PF03648.8 & 4 & 9 & 5 \\
\hline GH 26 & PF02156.9 & 5 & 10 & 6 & GH 76 & PF03663.8 & 0 & 1 & 1 \\
\hline GH 28 & PF00295.11 & 2 & 16 & 11 & GH 77 & PF02446.11 & 7 & 26 & 17 \\
\hline GH 30 & PF02055.10 & 3 & 8 & 11 & GH 81 & PF03639.7 & 0 & 0 & 1 \\
\hline GH 31 & PF01055.20 & 20 & 29 & 30 & GH 88 & PF07470.1 & 9 & 10 & 18 \\
\hline $\mathrm{GH} 32 \mathrm{C}$ & PF08244.6 & 0 & 5 & 0 & GH 92 & PF07971.6 & 34 & 49 & 46 \\
\hline GH $32 \mathrm{~N}$ & PF00251.14 & 4 & 4 & 3 & GH 97 & PF10566.3 & 15 & 49 & 26 \\
\hline GH 35 & PF01301.13 & 12 & 4 & 18 & GH 101 & PF12905.1 & 7 & 3 & 7 \\
\hline \multirow[t]{2}{*}{$\mathrm{GH} 38$} & PF01074.16 & 8 & 26 & 21 & $\mathrm{GH} C \mathrm{C}$ & PF11790.2 & 1 & 2 & 2 \\
\hline & & & & & \multicolumn{2}{|c|}{ Total number of counts } & 468 & 792 & 657 \\
\hline
\end{tabular}

Legend: Dynamic process in enzymology with time and substrate nature was observed in the bioreactors, the heightened GH and abundance (in bold) in the pretreated-sludge bioreactor were correlated with a higher sludge solubilization, and in turns a higher SCFA production.

plant in Yixing, China. The main features of WAS and AGS can be found in Additional file 4. The AGS was cultured in a laboratory up-flow anaerobic sludge bed (UASB) by synthetic wastewater (Additional file 5) prior to its use as the inoculum for methane production, where the use of synthetic wastewater for AGS culturing is a common practice in anaerobic digestion studies investigating the microbiology and biodegradability $[4,73,74]$. The hydrolytic retention time of UASB was $6 \mathrm{~h}$, and the AGS concentration in UASB was approximately $29165 \mathrm{mg} / \mathrm{L}$.

\section{Pretreatment of waste activated sludge}

Biogas-producing, anaerobic digester samples were obtained from a reproduction of the experiment described in our previous work [4], which introduced a new sludge pretreatment strategy ( $\mathrm{pH} 10$ for $8 \mathrm{~d}$ ) for enhanced methane production from WAS. During the pretreatment, the $\mathrm{pH}$ of the collected WAS was adjusted to 10.0 by addition of $5 \mathrm{M} \mathrm{NaOH}$ or $4 \mathrm{M} \mathrm{HCl}$ with an automatic titrator, in a tightly-sealed reactor which was mechanically stirred $(80 \mathrm{rpm})$ at $35 \pm 1^{\circ} \mathrm{C}$ for $8 \mathrm{~d}$. A blank test was also conducted, in which the sludge was not pretreated but mechanically stirred for $8 \mathrm{~d}$. Then the $\mathrm{pH}$ in all reactors was adjusted to $\mathrm{pH} 7.0$, and $30 \mathrm{~mL}$ of AGS was added to each reactor for methane production. All reactors were sealed with rubber stoppers and mechanically stirred at $80 \mathrm{rpm}$ without further $\mathrm{pH}$ control. The retention time of all reactors was $17 \mathrm{~d}$ and the organic loading rate was $1.88 \mathrm{~kg} / \mathrm{COD} / \mathrm{m}^{3} / \mathrm{d}$. The gas generation was detected by water displacement and the methane concentration was measured by a gas 
Table 4 Identification of carbohydrate binding module (CBM) family classified by CAZy database

\begin{tabular}{ccccc}
\hline & & \multicolumn{3}{c}{ Number of counts } \\
\cline { 4 - 5 } CAZy CBM family & Pfam model & UP30 & UP40 & P30 \\
\hline CBM_2 & PF00553.13 & 0 & 0 & 1 \\
CBM_4_9 & PF02018.11 & 1 & 5 & 6 \\
CBM_5_12 & PF02839.8 & 0 & 2 & 1 \\
CBM_6 & PF03422.9 & 2 & 6 & 8 \\
CBM_11 & PF03425.7 & 0 & 3 & 1 \\
CBM_20 & PF00686.13 & 0 & 4 & 3 \\
CBM_25 & PF03423.7 & 0 & 1 & 0 \\
CBM_48 & PF02922.12 & 11 & 10 & 20 \\
CBM_X & PF06204.5 & 4 & 7 & 11 \\
Total number of counts & $\mathbf{1 8}$ & $\mathbf{3 8}$ & $\mathbf{5 1}$
\end{tabular}

Legend: Dynamic process in enzymology with time and substrate nature was observed in the bioreactors, the heightened CBM abundance (in bold) in the pretreated-sludge bioreactor were correlated with a higher sludge solubilization, and in turns a higher SCFA production.

chromatograph (GC-14B, Shimadzu, Japan). The analyses of VSS were conducted in accordance with APHA Standard Methods [75]. In this study, the methane yield was reported as the amount of methane generated per gram of volatile suspended solid added ( $\mathrm{mL}-\mathrm{CH}_{4} / \mathrm{gVSS}$ added) unless otherwise stated. The full unit of methane

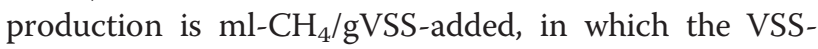
added refers to the initial VSS to facilitate comparison of methane production. Moreover, there was no SCFA in the original sludge before anaerobic fermentation, meaning that the initial VSS did not contain volatile fatty acids-hence the risk of overestimation of specific methane yield is improbable [4].

\section{Preparation of anaerobic digester samples}

The granular samples cultured with pretreated $(\mathrm{pH} 10$ for $8 \mathrm{~d}$ ) and un-pretreated WAS were collected when the methane production rate reached the maximum on day 17 , and then further cultured by a semi-continuous method to maintain the methane production rate. In replicates of three, the semi-continuous flow reactors with working volume of $1.0 \mathrm{~L}$ received $470 \mathrm{~mL}$ of $\mathrm{pH} 10$ pretreated sludge and un-pretreated sludge, respectively. Everyday, $52 \mathrm{~mL}$ sludge mixture was manually wasted from each reactor, and $52 \mathrm{~mL}$ pretreated and unpretreated sludge was added to the respective reactors; AGS was fed back to reactors by sifting the wasted sludge through a sifter with aperture of $0.2 \mathrm{~mm}$. Further procedure details were described in [4].

As a stable methane generation continued to be maintained by the semi-continuous culturing method, $50 \mathrm{~mL}$ anaerobic digester samples were collected from the pretreatment set-ups (as pooled sample) at day 30 (P30), control set-up at day 30 (UP30) and control set-up at day
40 (UP40) for microbial studies. The two samples collected at day 30 (P30, UP30) served to characterize taxonomic and functional difference between pretreated and unpretreated samples. Both sludge bioreactor were seeded with the same synthetic wastewater cultured AGS substrate, and later gradually replaced by the experimental sludge (pretreated or unpretreated WAS) completely as the batch experiment continued. Since both bioreactors received the same inoculums, therefore the only existing variable was the pretreatment, ascribing to the observed difference between the microbiomes. As for UP40, this additional un-pretreated sample at day 40 was prepared to provide further insight of the microbial dynamic in response to time. Figure 1 shows the experimental scheme for the preparation of the anaerobic digester samples.

\section{DNA extraction and 454 sequencing}

Samples (P30, UP30 and UP40) were kept at $-20^{\circ} \mathrm{C}$ and thawed once only for nucleic acid extraction using PowerSoil $^{\circledR}$ DNA Isolation Kit (Mobio, Carlsbad, USA), conducted within 24 hours of sample collection. DNA quantification was performed using Nanodrop 2000 spectrophotometer (Nanodrop Technologies, Wilmington, USA). Sequencing of total DNA derived from each was done by the shotgun sequencing approach on the 454 GS Junior system, and the sequencing quality was maintained by 454 propriety software. The raw sequence reads are submitted under the Sequence Read Archive (SRA) accession number SAMN01924662(P30), SAMN01924663 (UP30), SAMN01924664 (UP40).

\section{Metagenome analysis}

To obtain a quantitative picture of the taxonomic composition, sequence datasets were characterized without a prior assembly step [56]. The unassembled sequence reads were submitted to the online metagenome analysis tool Metagenome Rapid Annotation using Subsystem Technology (MG-RAST analysis pipeline 3.0) [76]. Following the quality trimming with default setting, taxonomic and functional profiling was performed using the M5 non-redundant protein database (M5NR) and KEGG Orthology (KO) reference database [54] Parameters used were e-value cutoff of $1 \times 10^{-5}$, minimum alignment length of 50 base pairs, and a minimum percentage identity at $50 \%$. Relative abundance of the Archaeal and Bacterial groups were determined by the percentages of respective reads over total assigned reads. Parallel processing was performed similarly on Megan4 to confirm the clustering pattern of taxonomic structure [77]. Only the taxonomic and functional annotation provided by MG-RAST was relied upon for all subsequent analysis.

To identify important carbohydrate- metabolism related gene candidates, pyrosequence reads were first subjected to gene prediction by a heuristic approach 
using MetaGeneMark 1.0 [69]. Next, the amino acid sequences were screened against catalytic domains (CD) characteristic for particular glycoside hydrolase $(\mathrm{GH})$ families or for a particular carbohydrate binding module (CBM) as classified by the CAZy database [68]. HMM models were downloaded from Pfam database version 25.0 and used as a database for pfam_scan [78] (e-value cutoff of $1 \times 10^{-4}$ ). Methanogenesis related gene candidates were identified with reference to KEGG and Metacyc pathway database [54,55].

\section{Additional files}

\section{Additional file 1: Taxonomic clustering of microbiome in} pretreated and un-pretreated sludge bioreactor at day 30 and 40 .

The clustering pattern revealed a proximate microbial resemblance between un-pretreated sludge bioreactors and the highly divergent community in pretreated sludge bioreactor impacted by the pretreatment.

\section{Additional file 2: Methanogenesis gene identifications in} pyrosequencing meta-datasets UP30, UP40, P30 using KO and SEED reference database. Genes related to methanogenesis were identified by comparing the pyrosequence meta-datasets UP30, UP40 and P30 with $K O$ and SEED database. Negative identifications were indicated as ' - '.

Additional file 3: Detailed profile related to (a) amino acid and (b) fat metabolism in the meta-datasets UP30, UP40 and P30 using KO reference database. Expression of these metabolism faculties in the unpretreated sludge bioreactor gradually elevated over time (compare UP30 and UP40), and were highest in pretreated-sludge bioreactor (P30). Label: [KO Map number] [metabolism detail] [path number]

\section{Additional file 4: Properties of WAS and AGS after settling.}

Description of data: All values are expressed in $\mathrm{mg} / \mathrm{L}$ except $\mathrm{pH}$. The data are the averages and their standard deviations in duplicate tests.

Additional file 5: Synthetic wastewater composition. Description of data: Chemical characterization of synthetic wastewater.

\section{Abbreviations}

AGS: Anaerobic granular sludge; CBM: Carbohydrate binding modules; CAZy: Carbohydrate-active enzyme; CD: Catalytic domains; GH: Glycosyl hydrolases; PPase: Inorganic pyrophosphatase; SRA: Sequence Read Archive; SCFAs: Short-chain fatty acids; USAB: Upward-flow anaerobic sludge blanket; VSS: Volatile suspended solid; WAS: Waste activated sludge;

WWTPs: Wastewater treatment plants.

\section{Competing interests}

The authors declare that they have no competing interests.

\section{Authors' contributions}

MTW performed the sample preparation, sequence analyses, data interpretation and compiled the manuscript. DZ carried out the anaerobic digestion and physical/chemical characterization. JL compiled the computational analyses tools. RKHH performed the next-generation sequencing. HMT, MSB and TJP contributed to data interpretation and manuscript's final revision. FCL and YC conceived and coordinated the study. All authors read and approved the final manuscript.

\section{Authors' information}

FCL is a Full Professor at School of Biological Sciences, former Dean of Faculty of Science, Board member of Initiative on Clean Energy and Environment, The University of Hong Kong, and Fellow of American Association for the Advancement of Science (AAAS). RKHH is a post-doc, JL, HMT, MSB and TJP are PhD students, MTW is an MPhil student in the same institution. YC is a Full Professor and DZ is a post-doc at State Key Laboratory of Pollution Control and Resources Reuse, School of Environmental Science and Engineering, Tongji University.

\section{Acknowledgements}

This study was partially supported by Initiative on Clean Energy and Environment, The University of Hong Kong (HKU-ICEE) and a Bioinformatics Center fund from Nanjing Agricultural University. We are grateful to $P$. Benzie, C. Bush and I. Tasovski for editing the manuscript.

\section{Author details}

${ }^{1} 5$ N01, Kadoorie Biological Sciences Building, School of Biological Sciences, The University of Hong Kong, Pokfulam Road, Hong Kong, Hong Kong. ${ }^{2}$ State Key Laboratory of Pollution Control and Resources Reuse, School of Environmental Science and Engineering, Tongji University, 1239 Siping Road, Shanghai 200092, China. ${ }^{3}$ Bioinformatics Center, Nanjing Agricultural University, Nanjing, China.

Received: 28 July 2012 Accepted: 6 March 2013 Published: 19 March 2013

\section{References}

1. Kim S, Kim J, Park C, Kim TH, Lee M, Kim SW, Lee J: Effects of various pretreatments for enhanced anaerobic digestion with waste activated sludge. J Biosci Bioeng 2003, 95:271-275.

2. Reynolds TDR, P A: Unit operations and process in environmental engineering. 2nd edition. Boston, MA, USA: PWS Publishing; 1996.

3. Jahng D, Cui R: Enhanced methane production from anaerobic digestion of disintegrated and deproteinized excess sludge. Biotechnol Lett 2006 28:531-538.

4. Zhang $D$, Chen $Y$, Zhao $Y$, Zhu X: New sludge pretreatment method to improve methane production in waste activated sludge digestion. Environ Sci Technol 2010, 44:4802-4808.

5. Weemaes M, Grootaerd H, Simoens F, Verstraete W: Anaerobic digestion of ozonized biosolids. Water Res 2000, 34:2330-2336.

6. Shin SG, Lee S, Lee C, Hwang K, Hwang S: Qualitative and quantitative assessment of microbial community in batch anaerobic digestion of secondary sludge. Bioresource Technol 2010, 101:9461-9470.

7. Mossakowska A, Hellstrom BG, Hultman B: Strategies for sludge handling in the Stockholm region. Water Sci Technol 1998, 38:111-118.

8. Odegaard H, Paulsrud B, Karlsson I: Wastewater sludge as a resource: sludge disposal strategies and corresponding treatment technologies aimed at sustainable handling of wastewater sludge. Water Sci Technol 2002, 46:295-303.

9. Riviere D, Desvignes V, Pelletier E, Chaussonnerie S, Guermazi S, Weissenbach J, Li T, Camacho P, Sghir A: Towards the definition of a core of microorganisms involved in anaerobic digestion of sludge. ISME J 2009, 3:700-714

10. Supaphol S, Jenkins SN, Intomo P, Waite IS, O'Donnell AG: Microbial community dynamics in mesophilic anaerobic co-digestion of mixed waste. Bioresource Technol 2011, 102:4021-4027.

11. Ting $C H$, Lin KR, Lee DJ, Tay JH: Production of hydrogen and methane from wastewater sludge using anaerobic fermentation. Water Sci Technol 2004, 50:223-228.

12. Raskin L, Griffin ME, McMahon KD, Mackie Rl: Methanogenic population dynamics during start-up of anaerobic digesters treating municipal solid waste and biosolids. Biotechnol Bioeng 1998, 57:342-355.

13. Stams AJ: Metabolic interactions between anaerobic bacteria in methanogenic environments. Antonie Van Leeuwenhoek 1994, 66:271-294.

14. Schink B: Syntrophic associations in methanogenic degradation. Prog Mol Subcell Biol 2006, 41:1-19.

15. Thauer RK: Biochemistry of methanogenesis: a tribute to Marjory Stephenson. 1998 Marjory Stephenson Prize Lecture. Microbiology 1998, 144(Pt 9):2377-2406

16. Li YY, Noike T: Upgrading of anaerobic-digestion of waste activatedsludge by thermal pretreatment. Water Sci Technol 1992, 26:857-866

17. Vlyssides AG, Karlis PK: Thermal-alkaline solubilization of waste activated sludge as a pre-treatment stage for anaerobic digestion. Bioresource Technol 2004, 91:201-206.

18. Neis U, Tiehm A, Nickel K, Zellhorn M: Ultrasonic waste activated sludge disintegration for improving anaerobic stabilization. Water Res 2001, $35: 2003-2009$

19. Tanaka S, Kobayashi T, Kamiyama K, Bildan MLNS: Effects of thermochemical pretreatment on the anaerobic digestion of waste activated sludge. Water Sci Technol 1997, 35:209-215. 
20. Wei H, Tucker MP, Baker JO, Harris M, Luo Y, Xu Q, Himmel ME, Ding SY: Tracking dynamics of plant biomass composting by changes in substrate structure, microbial community, and enzyme activity. Biotechnol Biofuels 2012, 5:20.

21. Lau MW, Gunawan C, Dale BE: The impacts of pretreatment on the fermentability of pretreated lignocellulosic biomass: a comparative evaluation between ammonia fiber expansion and dilute acid pretreatment. Biotechnol Biofuels 2009, 2:30.

22. Yuan HY, Chen YG, Zhang HX, Jiang S, Zhou Q, Gu GW: Improved bioproduction of short-chain fatty acids (SCFAs) from excess sludge under alkaline conditions. Environ Sci Technol 2006, 40:2025-2029.

23. He PJ, Yu GH, Shao LM, He PP: Toward understanding the mechanism of improving the production of volatile fatty acids from activated sludge at pH 10.0. Water Res 2008, 42:4637-4644.

24. Venter JC, Remington K, Heidelberg JF, Halpern AL, Rusch D, Eisen JA, Wu DY, Paulsen I, Nelson KE, Nelson W, et al: Environmental genome shotgun sequencing of the Sargasso Sea. Science 2004, 304:66-74.

25. Sogin ML, Morrison HG, Huber JA, Mark Welch D, Huse SM, Neal PR, Arrieta JM, Herndl GJ: Microbial diversity in the deep sea and the underexplored "rare biosphere". P Natl Acad Sci USA 2006, 103:12115-12120.

26. Krober M, Bekel T, Diaz NN, Goesmann A, Jaenicke S, Krause L, Miller D, Runte KJ, Viehover P, Puhler A, Schluter A: Phylogenetic characterization of a biogas plant microbial community integrating clone library 16S-rDNA sequences and metagenome sequence data obtained by 454pyrosequencing. J Biotechnol 2009, 142:38-49.

27. Hollister EB, Engledow AS, Hammett AJM, Provin TL, Wilkinson HH, Gentry TJ: Shifts in microbial community structure along an ecological gradient of hypersaline soils and sediments. ISME J 2010, 4:829-838.

28. Wirth R, Kovács E, Maróti G, Bagi Z, Rákhely G, Kovács KL: Characterization of a biogas-producing microbial community by short-read next generation DNA sequencing. Biotechnol Biofuels 2012, 5:4.

29. Zhang H, Banaszak JE, Parameswaran P, Alder J, Krajmalnik-Brown R, Rittmann BE: Focused-Pulsed sludge pre-treatment increases the bacterial diversity and relative abundance of acetoclastic methanogens in a full-scale anaerobic digester. Water Res 2009, 43:4517-4526.

30. Dinsdale EA, Edwards RA, Hall D, Angly F, Breitbart M, Brulc JM, Furlan M Desnues C, Haynes M, Li LL, et al: Functional metagenomic profiling of nine biomes. Nature 2008, 452:629-U628.

31. Okabe S, Ariesyady HD, Ito T: Functional bacterial and archaeal community structures of major trophic groups in a full-scale anaerobic sludge digester. Water Res 2007, 41:1554-1568.

32. Tanner RS: Biology of Anaerobic Microorganisms - Zehnder, Ajb. Science 1989, 245:201-202.

33. Deppenmeier U: The unique biochemistry of methanogenesis. Prog Nucleic Acid Re 2002, 71:223-283.

34. Blackall LL, Burrell PC, O'Sullivan C, Song H, Clarke WP: Identification, detection, and spatial resolution of Clostridium populations responsible for cellulose degradation in a methanogenic landfill leachate bioreactor. Appl Environ Microb 2004, 70:2414-2419.

35. Klocke M, Mahnert P, Mundt K, Souidi K, Linke B: Microbial community analysis of a biogas-producing completely stirred tank reactor fed continuously with fodder beet silage as mono-substrate. Syst Appl Microbiol 2007, 30:139-151.

36. Sekiguchi $Y$, Takahashi H, Kamagata Y, Ohashi A, Harada H: In situ detection, isolation, and physiological properties of a thin filamentous microorganism abundant in methanogenic granular sludges: a novel isolate affiliated with a clone cluster, the green non-sulfur bacteria, subdivision I. Appl Environ Microb 2001, 67:5740-5749.

37. Blackall LL, Bjornsson L, Hugenholtz P, Tyson GW: Filamentous Chloroflexi (green non-sulfur bacteria) are abundant in wastewater treatment processes with biological nutrient removal. Microbiol-Sgm 2002, 148:2309-2318.

38. Sekiguchi Y, Yamada T, Hanada S, Ohashi A, Harada H, Kamagata Y: Anaerolinea thermophila gen. nov., sp nov and Caldilinea aerophila gen. nov., sp nov., novel filamentous thermophiles that represent a previously uncultured lineage of the domain Bacteria at the subphylum level. Int J Syst Evol Micr 2003, 53:1843-1851.

39. Zakrzewski M, Goesmann A, Jaenicke S, Junemann S, Eikmeyer F Szczepanowski R, Al-Soud WA, Sorensen S, Puhler A, Schluter A: Profiling of the metabolically active community from a production-scale biogas plant by means of high-throughput metatranscriptome sequencing J Biotechnol 2012, 158:248-258.
40. Jaenicke S, Ander C, Bekel T, Bisdorf R, Droge M, Gartemann KH, Junemann S, Kaiser O, Krause L, Tille F, et al: Comparative and joint analysis of two metagenomic datasets from a biogas fermenter obtained by $454-$ pyrosequencing. PLoS One 2011, 6:e14519.

41. Liu WT, Lykidis A, Chen CL, Tringe SG, McHardy AC, Copeland A, Kyrpides NC, Hugenholtz P, Macarie H, Olmos A, Monroy O: Multiple syntrophic interactions in a terephthalate-degrading methanogenic consortium. ISME J 2011, 5:122-130.

42. Nelson MC, Morrison M, Yu Z: A meta-analysis of the microbial diversity observed in anaerobic digesters. Bioresour Technol 2011, 102:3730-3739.

43. Whitman WB, Liu YC: Metabolic, phylogenetic, and ecological diversity of the methanogenic archaea. Ann Ny Acad Sci 2008, 1125:171-189.

44. Raskin L, McMahon KD, Zheng DD, Stams AJM, Mackie Rl: Microbial population dynamics during start-up and overload conditions of anaerobic digesters treating municipal solid waste and sewage sludge. Biotechnol Bioeng 2004, 87:823-834.

45. Raskin L, Stroot PG, McMahon KD, Mackie Rl: Anaerobic codigestion of municipal solid waste and biosolids under various mixing conditions - I. Digester performance. Water Res 2001, 35:1804-1816.

46. Liesack W, Grosskopf R, Janssen PH: Diversity and structure of the methanogenic community in anoxic rice paddy soil microcosms as examined by cultivation and direct 16S rRNA gene sequence retrieval. Appl Environ Microb 1998, 64:960-969.

47. Shigematsu T, Tang Y, Kobayashi T, Kawaguchi H, Morimura S, Kida K: Effect of dilution rate on metabolic pathway shift between aceticlastic and nonaceticlastic methanogenesis in chemostat cultivation. Appl Environ Microbiol 2004, 70:4048-4052

48. Jetten MSM, Stams AJM, Zehnder AJB: Acetate threshold values and acetate activating enzymes in methanogenic bacteria. FEMS Microbiol Ecol 1990, 73:339-344.

49. Nettmann E, Bergmann I, Pramschufer S, Mundt K, Plogsties V, Herrmann C, Klocke M: Polyphasic analyses of methanogenic archaeal communities in agricultural biogas plants (vol 76, pg 2540, 2010). Appl Environ Microb 2011, 77:394-394.

50. Lee C, Kim J, Hwang K, O'Flaherty V, Hwang S: Quantitative analysis of methanogenic community dynamics in three anaerobic batch digesters treating different wastewaters. Water Res 2009, 43:157-165.

51. Smith KS, Ingram-Smith C: Methanosaeta, the forgotten methanogen? Trends Microbiol 2007, 15:150-155.

52. Smith DR, DoucetteStamm LA, Deloughery C, Lee HM, Dubois J, Aldredge T, Bashirzadeh R, Blakely D, Cook R, Gilbert K, et al: Complete genome sequence of Methanobacterium thermoautotrophicum Delta $\mathrm{H}$ : Functional analysis and comparative genomics. J Bacteriol 1997, 179:7135-7155.

53. Boone DW WB, Rouviere P: Diversity and taxonomy of methanogens. In Methanogenesis ecology, physiology, biochemistry \& genetics. Edited by JG F. New York: Chapman \& Hall; 1993:35-80

54. Kanehisa M, Goto S: KEGG: Kyoto Encyclopedia of Genes and Genomes. Nucleic Acids Res 2000, 28:27-30.

55. Karp PD, Caspi R, Foerster H, Fulcher CA, Kaipa P, Krummenacker M, Latendresse M, Paley S, Rhee SY, Shearer AG, et al: The MetaCyc Database of metabolic pathways and enzymes and the BioCyc collection of Pathway/Genome Databases. Nucleic Acids Res 2008, 36:D623-D631.

56. Krause L, Diaz NN, Edwards RA, Gartemann KH, Kromeke H, Neuweger H, Puhler A, Runte KJ, Schluter A, Stoye J, et al: Taxonomic composition and gene content of a methane-producing microbial community isolated from a biogas reactor. J Biotechnol 2008, 136:91-101.

57. Metcalf WW, Rother M: Anaerobic growth of Methanosarcina acetivorans C2A on carbon monoxide: An unusual way of life for a methanogenic archaeon. P Natl Acad Sci USA 2004, 101:16929-16934.

58. Singhwissmann K, Ferry JG: Transcriptional regulation of the phosphotransacetylase-encoding and acetate kinase-encoding genes (Pta and Ack) from methanosarcina-thermophila. J Bacteriol 1995, 177:1699-1702.

59. Frolund B, Griebe T, Nielsen PH: Enzymatic-activity in the activated-sludge floc matrix. Appl Microbiol Biot 1995, 43:755-761.

60. Gessesse A, Dueholm T, Petersen SB, Nielsen PH: Lipase and protease extraction from activated sludge. Water Res 2003, 37:3652-3657.

61. Pletschke Bl, Burgess JE: Hydrolytic enzymes in sewage sludge treatment: A mini-review. Water Sa 2008, 34:343-349.

62. Carrere H, Dumas C, Battimelli A, Batstone DJ, Delgenes JP, Steyer JP, Ferrer I: Pretreatment methods to improve sludge anaerobic degradability: a review. J Hazard Mater 2010, 183:1-15. 
63. Cescutti P, Toffanin R, Pollesello P, Sutherland IW: Structural determination of the acidic exopolysaccharide produced by a Pseudomonas sp. strain 1.15. Carbohydr Res 1999, 315:159-168.

64. Sutherland IW, Kennedy L: Polysaccharide lyases from gellan-producing Sphingomonas spp. Microbiology 1996, 142(Pt 4):867-872.

65. Li LL, McCorkle SR, Monchy S, Taghavi S, van der Lelie D: Bioprospecting metagenomes: glycosyl hydrolases for converting biomass. Biotechnol Biofuels 2009, 2:10

66. Rubin EM, Hess M, Sczyrba A, Egan R, Kim TW, Chokhawala H, Schroth G, Luo SJ, Clark DS, Chen F, et al: Metagenomic discovery of biomassdegrading genes and genomes from Cow rumen. Science 2011, 331:463-467.

67. Suen G, Scott JJ, Aylward FO, Adams SM, Tringe SG, Pinto-Tomas AA, Foster CE, Pauly M, Weimer PJ, Barry KW, et al: An insect herbivore microbiome with high plant biomass-degrading capacity. PLoS Genet 2010, 6(9): e1001129.

68. Cantarel BL, Coutinho PM, Rancurel C, Bernard T, Lombard V, Henrissat B. The Carbohydrate-Active EnZymes database (CAZy): an expert resource for Glycogenomics. Nucleic Acids Res 2009, 37:D233-238.

69. Zhu W, Lomsadze A, Borodovsky M: Ab initio gene identification in metagenomic sequences. Nucleic Acids Res 2010, 38:e132.

70. Li LL, Taghavi S, McCorkle SM, Zhang YB, Blewitt MG, Brunecky R, Adney WS, Himmel ME, Brumm P, Drinkwater C, et al: Bioprospecting metagenomics of decaying wood: mining for new glycoside hydrolases. Biotechnol Biofuels 2011, 4:23.

71. Chu LB, Wang JL, Wang B, Xing XH, Yan ST, Sun XL, Jurcik B: Changes in biomass activity and characteristics of activated sludge exposed to low ozone dose. Chemosphere 2009, 77:269-272.

72. Wei YS, Van Houten RT, Borger AR, Eikelboom DH, Fan YB: Minimization of excess sludge production for biological wastewater treatment. Water Res 2003, 37:4453-4467.

73. Bassin JP, Pronk M, Muyzer G, Kleerebezem R, Dezotti M, van Loosdrecht MCM: Effect of elevated salt concentrations on the aerobic granular sludge process: linking microbial activity with microbial community structure. Appl Environ Microb 2011, 77:7942-7953.

74. del Rio AV, Morales N, Isanta E, Mosquera-Corral A, Campos JL, Steyer JP, Carrere $\mathrm{H}$ : Thermal pre-treatment of aerobic granular sludge: Impact on anaerobic biodegradability. Water Res 2011, 45:6011-6020.

75. Eaton AD, Franson MAH, Association APH: Association AWW. Standard Methods for the Examination of Water \& Wastewater. Federation WE: American Public Health Association; 1998.

76. Meyer F, Paarmann D, D'Souza M, Olson R, Glass EM, Kubal M, Paczian T, Rodriguez A, Stevens R, Wilke A, et al: The metagenomics RAST server - a public resource for the automatic phylogenetic and functional analysis of metagenomes. BMC Bioinforma 2008, 9:386

77. Huson DH, Mitra S, Ruscheweyh HJ, Weber N, Schuster SC: Integrative analysis of environmental sequences using MEGAN4. Genome Res 2011, 21:1552-1560.

78. Eddy SR: Profile hidden markov models. Bioinformatics 1998, 14:755-763.

doi:10.1186/1754-6834-6-38

Cite this article as: Wong et al:: Towards a metagenomic understanding on enhanced biomethane production from waste activated sludge after pH 10 pretreatment. Biotechnology for Biofuels 2013 6:38.

\section{Submit your next manuscript to BioMed Central and take full advantage of:}

- Convenient online submission

- Thorough peer review

- No space constraints or color figure charges

- Immediate publication on acceptance

- Inclusion in PubMed, CAS, Scopus and Google Scholar

- Research which is freely available for redistribution

Submit your manuscript at www.biomedcentral.com/submit
C Biomed Central 